\title{
Inhibitory Effect of Polysaccharides from Scutellaria barbata D. Don on Invasion and Metastasis of 95-D Cells Lines via Regulation of C-MET and E-CAD Expressions
}

\author{
Xiao-Kun Yang ${ }^{1,2}$, Ya-Dong Yang ${ }^{1}$, Shu-Qian Tang ${ }^{1}$, Ling $\mathrm{Xu}^{1}$, Gui-Hong Yang ${ }^{1}$, \\ Qiao-Yu Xu ${ }^{1}$, Hui Tang ${ }^{1}$ and Jin-Jin $W_{u^{1 *}}$ \\ ${ }^{1}$ Department of Dermatology, Research Institute of Wound Healing and Tissue Engineering of Chongqing, Daping Hospital, \\ The Third Military Medical University, Chongqing, 400042, ${ }^{2}$ Department of Emergency, General Hospital of Chengdu Military \\ Command Area, Chengdu 610083, Sichuan Province, PR China
}

*For correspondence: wujjtmmu@126.com; Tel: +86 023-68757599 ; Fax : +86 023-68757599

Received: 17 April 2013

Revised accepted: 3July 2013

\begin{abstract}
Purpose: To investigate the inhibitory effect of polysaccharides from Scutellaria barbata (PSB) on invasion and metastasis of lung cancer, and study the possible mechanism.

Methods: PSB was extracted with water and by alcohol precipitation, and purified by DEAE-52 column chromatography. A highly invasive and metastatic lung carcinoma cell, 95-D cell line, was used for the study. Cell adhesion and invasion assays in vitro were performed to evaluate the anti-invasive and antimetastatic effects of PSB (50-200 $\mathrm{\mu g} / \mathrm{ml})$ on 95-D cell. Immunocytochemical staining and Western blot techniques were employed to study the regulatory effects of PSB on the expression of C-MET and E$C A D$.

Results: The results indicate that PSB significantly inhibited cell invasion and migration of 95-D in a concentration-dependent manner $(p<0.05)$. The adhesion of 95-D cells to fibronectin was also inhibited by PSB $(p<0.05)$. The expression of C-MET and E-CAD in 95-D cells treated with PSB were significantly down-regulated and up-regulated, respectivelt $(p<0.05)$.

Conclusion: Treatment with PSB can significantly inhibit the invasion and metastasis of 95-D cells in vitro, probably through the regulation of C-MET and E-CAD.
\end{abstract}

Keywords: Polysaccharide, Scutellaria barbata, 95-D cell lines, Invasion, Metastasis

Tropical Journal of Pharmaceutical Research is indexed by Science Citation Index (SciSearch), Scopus, International Pharmaceutical Abstract, Chemical Abstracts, Embase, Index Copernicus, EBSCO, African Index Medicus, JournalSeek, Journal Citation Reports/Science Edition, Directory of Open Access Journals (DOAJ), African Journal Online, Bioline International, Open-J-Gate and Pharmacy Abstracts

\section{INTRODUCTION}

Lung carcinoma is one of the leading causes of cancer deaths in both men and women worldwide [1-2]. Lung cancers are classified as small cell lung cancer (SCLC) and non-small cell lung cancer (NSCLC). NSCLC constitutes approximately $75 \%$ of lung cancer cases. It is well known that lung cancers are associated with a substantial risk of invasion and metastasis [34]. Tobacco smoke is the predominant etiologic risk factor for lung cancers. In addition, polycyclic aromatic hydrocarbons are reported to be the major causative agents for development of lung cancers among cigarette smoke components [5]. Although improvements have been made in diagnosis and treatment of lung cancers, it remains an aggressive cancer with a poor prognosis, and tissue invasion and metastasis are one of the primary causes of the mortality of lung cancers patients [6]. In recent years, more and more people have begun to recognize traditional Chinese medicine (TCM) as a potential source of new anti-cancer drugs $[7,8]$ and some studies have isolated novel 
compounds with therapeutic activities from TCMs $[9,10]$.

Scutellaria barbata D. Don, a perennial herb belonging to the family Lamiaceae, is widely distributed throughout China and Korea. It has been traditionally used in folk medicine as antiinflammatory and anti-tumor agents [11, 12]. $S$. barbata is known to contain a large number of polysaccharides, alkaloids, flavones, organic acid, and neo-clerodane diterpenoids [13-15]. However, there has been no report regarding the inhibitory effect of PSB on invasion and metastasis of lung cancers thus far. The present investigation is aimed ay achieving this as well as elucidate the possible mechanism involved.

\section{EXPERIMENTAL}

\section{Plant material}

Scutellaria barbata was purchased from the Hehuachi Market of Traditional Chinese Herbs and identified by Professor Yong Chen of Chengdu Academy of the Chinese Materia Medica (Chengdu, China). A voucher specimen of this herb (S-2011-0901) was kept in the institutional herbarium.

\section{Cell lines}

The highly invasive and metastatic lung carcinoma cell line, human 95-D Human cells was obtained from Chinese Academy of Science Cellbank (CAS, Shanghai, China). Cells were cultured in RPMI 1640 medium supplemented with $15 \%(v / v)$ heat-inactivated fetal bovine serum (FBS), $100 \mathrm{mg} / \mathrm{ml}$ streptomycin and 100 $\mathrm{U} / \mathrm{ml}$ penicillin at $37{ }^{\circ} \mathrm{C}$ in a humidified and $5 \%$ $\mathrm{CO}_{2}$ atmosphere.

\section{Chemicals}

Silica-gel was purchased from Qingdao Haiyang Chemical Co, Ltd. (Qingdao, China), DEAE-52 was purchased from Whatman Ltd. (Maidstone, UK). The RPMI 1640 media and fetal bovine serum (FBS) were purchased from Invitrogen (Carlsbad, USA). Transwell well culture chambers were purchased from Corning (New York, USA). Matrigel was obtained from Collaborative Research Inc. (Bedford, USA). Fibronectin and 3-(4, 5-dimethylthiazol-2-yl)-2, 5diphenyltetrazolium bromide (MTT) were obtained from Sigma (St. Louis, USA). All other chemicals used in this study were of analytical reagent grade.

\section{Isolation of polysaccharides from S. barbata}

PSB was prepared by the method described previously by Song et al [16] with minor modification. In brief, the crude polysaccharides were extracted by the traditional technique of water extraction and alcohol precipitation. The dried and crushed $S$. barbata was extracted four times (each extraction period lasting $2 \mathrm{~h}$ ) with deionized water by decoction at $90{ }^{\circ} \mathrm{C}$. After filtration, the resulting extract was mixed with 4 volumes of dehydrated ethanol (ethanol final concentration, $80 \%$ ) and kept overnight at $4{ }^{\circ} \mathrm{C}$ in a refrigerator. Thereafter, the mixture was centrifuged at $4000 \mathrm{rpm} / \mathrm{min}$ for $10 \mathrm{~min}$, washed 4 times with dehydrated ethanol, and the precipitate was collected as crude PSB. Subsequently, DEAE-52 column chromatography was used to purify the crude PSB with $\mathrm{NaCl}$ solution (0 2 $\mathrm{mol} / \mathrm{l})$.

\section{MTT assay}

The viability of cells was monitored after various concentrations of PSB treatment. MTT assay was carried out using standard protocol and optical density (OD) was read at $570 \mathrm{~nm}$ according to the method of previous reported [17]. Assays were performed in triplicate on three independent experiments.

\section{In vitro invasion assay}

The invasive activity of the 95-D cells was evaluated in a Transwell cell culture chamber using a method described previously [18]. Cell invasion assays were performed using $8.0 \mu \mathrm{m}$ pore size Transwell well culture chambers which were coated with $500 \mu \mathrm{g} / \mathrm{ml}$ of Matrigel. The coated filters were washed thoroughly in PBS and dried immediately before use. Ten percent FBS-RPMI 1640 was placed in the lower chamber, and 95-D cells ( $2 \times 10^{5} /$ chamber $)$ in RPMI 1640 were placed in the upper chamber. The PSB solution was added to the upper chamber and incubated for $12 \mathrm{~h}$ at $37{ }^{\circ} \mathrm{C}$ in $5 \%$ $\mathrm{CO}_{2}$. The number of the invaded cells through Matrigel-coated PVPF filter was measured by counting cells stained with $0.2 \%$ crystal violet solution.

\section{Wound-healing assay}

Wound-healing assay was carried out using the method described previously [19]. 95-D cells were cultured in 6-well plates, and a sterile pipette $(200 \mu \mathrm{L})$ was used to scratch the cells to form a wound. Cells were washed once with cold 1x PBS buffer, and treated with different 
concentrations of PSB for $48 \mathrm{~h}$. Migration of the cells was evaluated at $48 \mathrm{~h}$.

\section{Cell adhesion assay}

Cell attachment assay was carried out in 96-well plates according the method described previously [20]. The wells were precoated with 50 $\mu \mathrm{l}$ of $5 \mu \mathrm{g} / \mathrm{ml}$ fibronectin overnight at room temperature and blocked with $0.2 \mathrm{ml}$ of RPMI 1640/well containing $3 \%$ BSA for $1 \mathrm{~h}$ at $37^{\circ} \mathrm{C}$. They were then re-suspended in RPMI 1640 containing $0.1 \%$ BSA, added $\left(5 \times 10^{5} / \mathrm{ml}, 0.2\right.$ $\mathrm{ml} /$ well) to each well and the PSB was added. This suspension was incubated at $37^{\circ} \mathrm{C}$ for $1 \mathrm{~h}$. The wells were washed twice with warm PBS to remove the unattached cells, and the attached cells were then stained with a $0.2 \%$ crystal violet aqueous solution in $20 \%$ methanol for $10 \mathrm{~min}$. Once stained, the cells were dissolved in $200 \mu \mathrm{l}$ of a $1 \%$ sodium dodecyl sulfate (SDS) solution, and the optical density was measured at $560 \mathrm{~nm}$ using a microplate reader.

\section{Western blot test}

C-MET and E-CAD expressions were examined by western blotting. The 95-D cells were treated with different concentrations of PSB for $72 \mathrm{~h}$. Then, cells were harvested in lysis buffer after treated with different concentrations of PSB and homogenized by sonification. Then, equal amounts of protein $(40 \mu \mathrm{g})$ were separated by sodium dodecyl sulfate/polyacrylamidegel electrophoresis (SDS/PAGE) on $8 \%$ gels, blotted on polyvinylidene difluoride (PVDF), and probed with anti-E Cadherin and anti-C Met rabbit monoclonal antibody (Abcam Biotechnology, UK) and subsequently with goatanti-rabbit (HRP), and detected by chemiluminescence. To measure protein loading, antibodies directed against $\beta$-actin were used.

\section{Immuno-cytochemical staining}

Immuno-cytochemical staining assay was performed according to the method described on the commercial kits to examine the expressions of C-MET and E-CAD (Abcam Biotechnology, UK).

\section{Statistical analysis}

All the results are expressed as Mean \pm SD. The statistical significance of differences was analyzed using SPSS software (SPSS for Windows 16.0, USA). The significance of the mean difference was determined by one-way ANOVA, followed by a LSD-t test for multi group comparisons. Probability values $(p)<0.05$ were considered significant.

\section{RESULTS}

\section{Cytotoxic effect of PSB on the 95-D cells}

MTT assay was carried out to select a suitable concentration to investigate the inhibitory effect of PSB on cell invasion and metastasis. As shown in Fig. 1, PSB at the concentrations > 300 $\mu \mathrm{g} / \mathrm{ml}$ showed slight effect on the survival of cells. On the other hand, PSB had no inhibitory effect on the growth of 95-D cells after $24 \mathrm{~h}$ incubation at concentrations of 50 to $200 \mathrm{mg} / \mathrm{ml}$, which was used in the present study.

\section{In vitro invasion and wound healing}

PSB effectively inhibited the cell invasion of 95-D in a dose-dependent manner, and an approximately $60 \%$ reduction was achieved at $200 \mu \mathrm{g} / \mathrm{ml}$ (Fig. 2a). In addition, wound healing rates in the 95-D cells treated with different doses of PSB were reduced, in a dosedependent manner (Fig 2b).

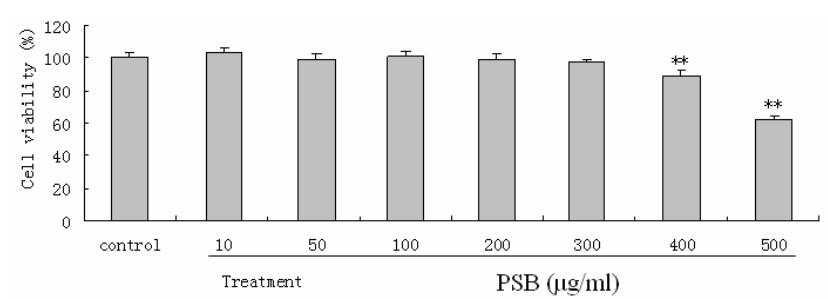

Figure 1: Viability of 95-D cells treated with PSB at different concentrations. Data are mean $\pm S D(n=3)$; ${ }^{*} p<0.05,{ }^{* *} p<0.01$.

\section{Cell adhesion}

The PSB inhibited the adhesion of 95-D cells to the fibronectin in a concentration-dependent manner, and an approximately $50 \%$ reduction was achieved at $200 \mu \mathrm{g} \mathrm{/ml} \mathrm{(Fig} \mathrm{3).}$

\section{Effect of PSB on expressions of C-MET and E-CAD}

Expressions of C-MET of the 95-D cells treated with PSB were down-regulated, in a concentration-dependent manner, compared with control group (Figs 4 and 5). However, the expressions of E-CAD in the 95-D cells treated with PSB were significantly up-regulated, in a concentration-dependent manner, compared to control group (Figs 4 and 6). 

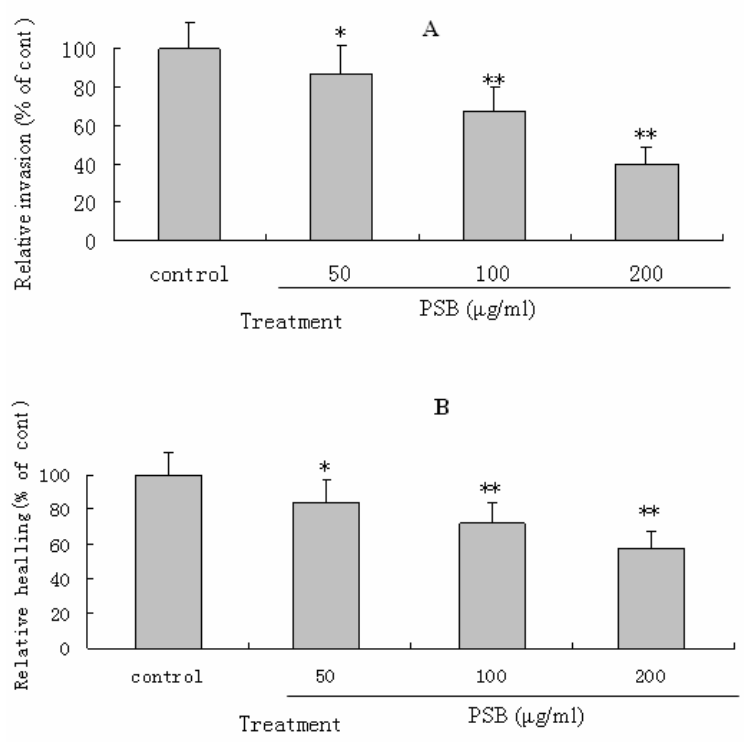

Figure 2: In vitro invasion and wound healing: (A) 95$D$ cells treated with different concentrations of PSB for $12 \mathrm{~h}$, and cells invaded at the lower surface counted; (B) 95-D cells treated with different concentrations of PSB for $24 \mathrm{~h}$, and migration of the cells evaluated after 48 h. Data are expressed as \% of control, and as mean $\pm \mathrm{SD}(\mathrm{n}=3) ;{ }^{*} p<0.05,{ }^{* *} p<0.01$

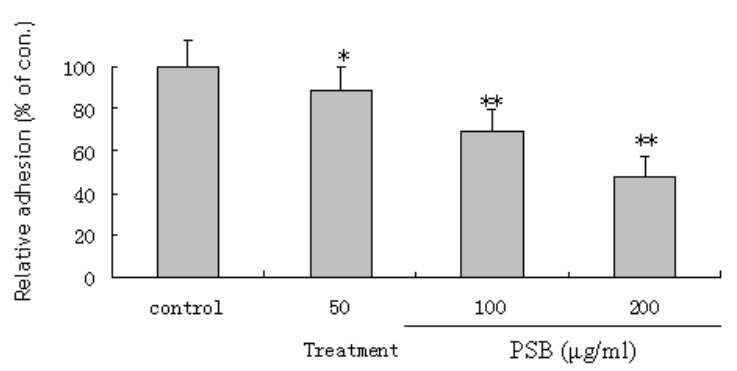

Figure 3: Cell adhesion following treatment. Cell adhesion is expressed as \% of control, and as mean \pm $\mathrm{SD}(\mathrm{n}=3) ;{ }^{*} p<0.05,{ }^{* *} p<0.01$

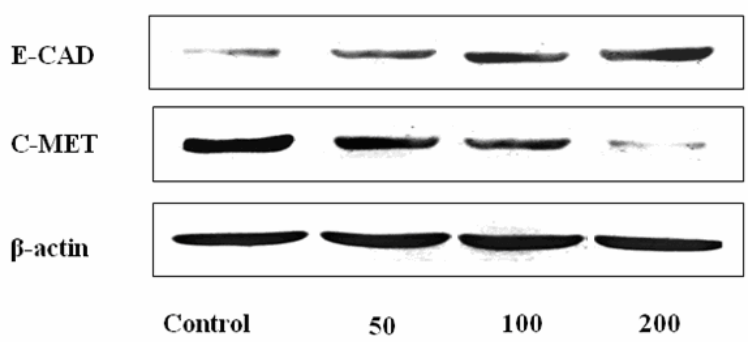

Figure 4: Effect of PSB on expression of C-MET and E-CAD.

\section{DISCUSSION}

Traditional Chinese medicines (TCM) have been used for more than millennium in China to prevent and alleviate a wide variety of diseases. Some anti-invasive and anti-metastatic agents for treatment of cancer have been derived from TCM [21]. In the present study, we report the inhibitory effect of PSB on invasion and metastasis of lung cancers cell lines for the first time.
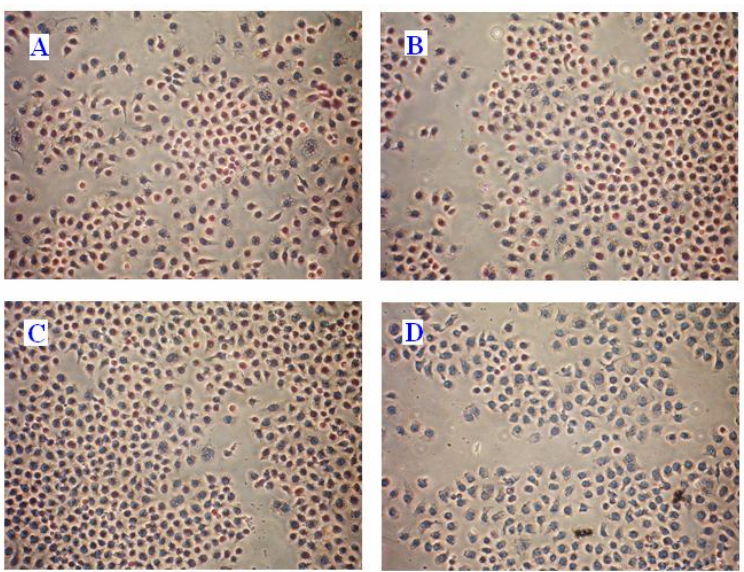

Figure 5: Expression of C-MET as observed by immunocytochemical staining; 95-D cells were treated with different concentrations of PSB for $72 \mathrm{~h}$. The analyzed sections stained for anti-C Met rabbit monoclonal antibody (brown). A, B, C and D represent control, and PSB concentrations of $50,100,200 \mu \mathrm{g} / \mathrm{ml}$, respectively (Magnification, $\times 200$ )
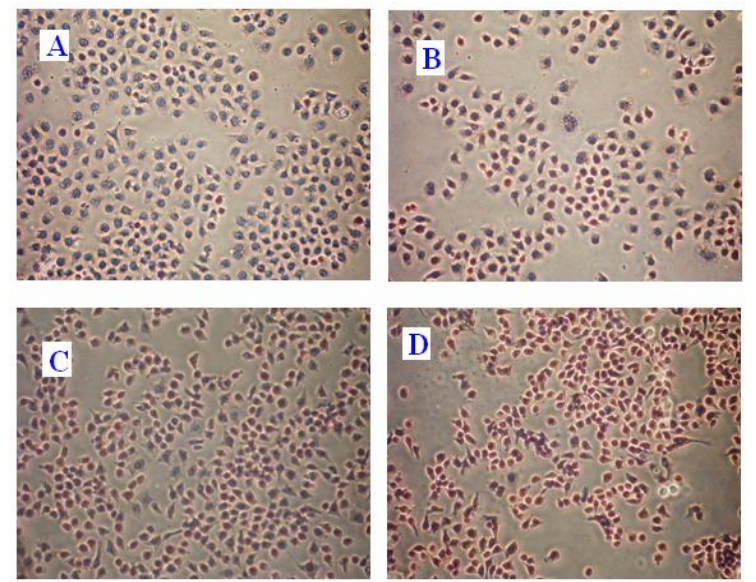

Figure 6: Expression of E-CAD as observed by immunocytochemical staining. The 95-D cells were treated with different concentrations of PSB for $72 \mathrm{~h}$. The analyzed sections stained for anti-E Cadherin rabbit monoclonal antibody (brown). A, B, C and D represent control, and PSB concentrations of 50, 100, $200 \mu \mathrm{g} / \mathrm{ml}$, respectively (Magnification, ×200)

Tumor cells invasion to the extracellular matrix (ECM) is an important step in the process of tumor metastasis [22], and the ECM were composited with basement membrane (BM) and intercellular substance. This results of our present study demonstrated that PSB inhibits the invasion of 95-D cells to the BM in vitro. In addition, tumor cell adhesion to the ECM is another key step in metastasis formation of tumor. Previous studies have demonstrated that alterations in the adhesive properties of tumor cells correlate with progression to tumor malignancy; additionally, the increasing 
evidences now indicate that an aberrant tumor cell adhesion is causally involved in tumor progression and metastasis [22, 22]. In our present study, we demonstrated that the PSB significantly inhibited the adhesion of 95-D cells to the fibronectin, in a concentration-dependent manner. Additionally, the results of MTT assay suggested that the inhibitions of 95-D cell adhesion, invasion and migration are not due to the cytotoxicity of PSB.

Tumor invasion and metastasis are the hallmarks of tumor malignancy, frequently coincide with the loss of E-cadherin (E-CAD). E-CAD is a calciumdependent membrane glycoprotein that has important effects on the maintenance of cell-cell adhesion, preservation of epithelial tissue polarity, and structural integrity [22,20,24]. E$\mathrm{CAD}$ expression is commonly down-regulated in a wide variety of human malignancies, such as lung cancers, skin cancer, oral squamous carcinoma, and reduced E-CAD expression has been shown to be an indicator of unfavorable prognosis in malignancies [25].

C-MET is a transmembrane tyrosine kinase receptor that mediates the oncogenic activities of the hepatocyte growth factor (HGF). Overexpression of C-MET has been shown to contribute to progression and dissemination of several malignancies including lung cancers [25, 26]. Previous studies have indicated that the inverse correlation between the expression of HGF/C-MET and membrane E-CAD expression in tumors [26,27], suggesting that these proteins may be useful markers of malignant transformation. In the results of our present study, we found that the expressions of C-MET by $95-D$ cells treated with PSB were downregulated, while, expressions of E-CAD of 95-D cells treated with PSB were significantly upregulated. Therefore, inhibition of 95-D cell adhesion and invasion is possibly due to the regulation of $\mathrm{C}-\mathrm{MET}$ and $\mathrm{E}-\mathrm{CAD}$ expressions by PSB.

\section{CONCLUSION}

Treatment with PSB can significantly inhibit the invasion and metastasis of 95-D cells lines in vitro, due probably to the regulation of C-MET and E-CAD by PSB. Consequently, PSB might be useful for the treatment of lung cancers.

\section{ACKNOWLEDGMENT}

This work was supported by National Natural Science Foundation of China (no. 31170924) and National 863 Plant Projects Foundation of China (no. 2012AA020504-4).

\section{REFERENCES}

1. Jemal $A$, Siegel $R$, Ward $E$. Cancer statistics. $C A$ Cancer J Clin 2007; 57: 43-66.

2. Wen J, Fu JH, Zhang W, Guo M. Genetic and epigenetic changes in lung carcinoma and their clinical implications. Modern Pathol 2011; 24: 932-943.

3. Hu R, Wu R, Deng J, Lau DA. Small proline-rich protein, spr1: Specific marker for squamous lung carcinoma. Lung Cancer 1998; 20: 25-30.

4. Liu $Y$, Sun $W Y$, Zhang KT, Zheng HW, Ma Y, Lin DM. Identification of genes differentially expressed in human primary lung squamous cell carcinoma. Lung Cancer 2007; 56:307-317.

5. Tamura A, Hebisawa A, Hayashi K, Sagara YZ, Fukushima K, Kurashima A. Prognostic significance of thrombomodulin expression and vascular invasion in stage I squamous cell carcinoma of the lung. Lung Cancer 2001; 34: 375382.

6. Smith EL, Denissenko MF, Bennett WP, Li HY, Amin S, Tang MS, Pfeifer GP. Targeting of Lung Cancer Mutational Hotspots by Polycyclic Aromatic Hydrocarbons. JNCI J Natl Cancer Inst 2000; 92: 803-811.

7. Li XJ, Zhang HY. Western healers in traditional Chinese medicine. EMBO reports 2008; 9: 112-113.

8. Schmidt BM, Ribnicky DM, Lipsky PE, Raskin I. Revisiting the ancient concept of botanical therapeutics. Nat Chem Biol 2007; 3: 360-366.

9. Peng W, Guo L, Zheng CJ, Zhang QY, Zhang H, Huang BK. Two new azaphilone alkaloids dimers from endophytic Chaetomium fusiform of the liverwort Scapania verrucosa Heeg. Biochem Syst Ecol 2012; 45:124-126.

10. Meng Z, Garrett CR, Shen Y, Liu L, Yang P, Huo Y. Prospective randomized evaluation of Traditional Chinese Medicine combined with chemotherapy: a randomize phase III study of wild toad extract plus gemcitabine in patients with advanced pancreatic adenocarcinomas. $\mathrm{Br} J$ Cancer 2012; 107: 411416.

11. Ye CL, Huang Q. Extraction of polysaccharides from herbal Scutellaria barbata D. Don (Ban-Zhi-Lian) and their antioxidant activity. Carbohyd Polym 2012; 89:1131-1137.

12. 11.Yin, X.L.; Zhou, J.B.; Jie, C.F.; Xing, D.M.; Zhang, Y. Anticancer activity and mechanism of Scutellaria barbata extract on human lung cancer cell line A549. Life Sci 2004, 75, 2233-2244.

13. Jiangsu New Medical College, editor. Dictionary of Chinese Materia Medica. Shanghai: Science and Technology Press of Shanghai; 1977.

14. Dai SJ, Tao JY, Liu K, Jiang YT, Shen L. neo-Clerodane diterpenoids from Scutellaria barbata with cytotoxic activities Phytochem 2006; 67:1326-1330.

15. Wang G, Wang F, Liu JK. Two New Phenols from Scutellaria barbata Molecules 2011; 16:1402-1408.

16. Song GC, Yu YJ, Wang XJ. Experiments on Antitumor Activity and Immunological Mechanisms of Scutellaria Barbata Polysaccharides. Mode Tradit Chin Med Mater Med 2011; 13: 641-643.

17. Kim SM, Choi J, Kim JB, Nam SJ, Yang JH, Kim JH. Berberine Suppresses TNF- $\alpha$-induced MMP-9 and Cell Invasion through Inhibition of AP-1 Activity in MDA-MB-231 Human Breast Cancer Cells. Molecules 2008; 13:2975-2985.

18. Han XD, Yan DM, Zhao XF, Hiroshi $M$, Ding WG, Li $P$. Octapeptide $(P-5 m)$ Inhibits Metastasis of HCCLM3 Cell Lines via Regulation of MMP-2 Expression in in Vitro and in Vivo Studies. Molecules 2012; 17: 1357-1372.

19. He J, Xu Q, Wang M, Li CY, Qian X, Shi ZM. Oral Administration of Apigenin Inhibits Metastasis through AKT/P70S6K1/MMP-9 Pathway in

Trop J Pharm Res, August 2013;12 (4): 521 
Orthotopic Ovarian Tumor Model. Int. J. Mol. Sci. 2012; 13: 7271-7282.

20. Zhang $Y$, Zhang SL (2008) Inhibition effect of GuizhiFuling-decoction on the invasion of human cervical cancer.J Ethnopharmacol 120: 25-35.

21. Cavallaro U, Christofori $G$ (2001) Cell adhesion in tumor invasion and metastasis: loss of the glue is not enough. Biochim Biophys Acta 1552:39-45.

22. Kalluri $R$, RWeinberg RA (2009) The basics of epithelialmesenchymal transition. J. Clin. Invest. 119:1420 1428.

23. Shiozaki $H$, Oka $H$, Inoue $M$, Tamura $S$, Monden $M$ (1996) E-cadherin mediated adhesion system in cancer cells. Cancer 77:1605-1613.

24. Martínez A, Spencer ML, Borlando J, Flores M, Rojas IG (2011) E-cadherin and c-Met expression in actinic cheilits and lip squamous cell carcinoma. Rehabil. Oral 4: 122-125.
25. Dohadwala $M$, Yang SC, Luo J, Sharma S, Batra RK Huang M (2006) Cyclooxygenase-2-dependent regulation of E-cadherin: Prostaglandin $E(2)$ induces transcriptional repressors ZEB1 and snail in non-small cell lung cancer. Cancer Res 15: 5338-5345.

26. Yang L, Liu M, Deng CZ, Gu ZK, Gao YL (2012) Expression of transforming growth factor- $\beta 1$ (TGF$\beta 1)$ and E-cadherin in glioma. Tumor Biol. DOI 10.1007/s13277-012-0398-z.

27. Kim CH, Kim J, Kahng H, Choi EC (2007) Change of Ecadherin by hepatocyte growth factor and effects on the prognosis of hypopharyngeal carcinoma. Ann Surg Oncol 14: 1565-1574. 